\title{
Semantic Types of Subjects and Objects of the Verb LIE in American Corpus (COCA)
}

\author{
Elvi Citraresmana \\ elvi.citraresmana@unpad.ac.id \\ Universitas Padjadjaran
}

\begin{abstract}
This research discusses semantic types of subjects and objects of the verb lie and the phenomena of the usage of verb in American Corpus (COCA) from 1990 to 2012. This research describes the subjects who told lies frequently and the objects who received the lies from the subjects and what topics American usually had when they lied. The verb lie has two meanings, they are 'not telling the truth' and 'to recline or lie down'. In this research, the verb lie refers to the meaning of 'not telling the truth'. The corpus does not divide between those two meanings, so the writer collected and divided them manually. After that, the prospective ones were categorized based on frequency $(\mathrm{F})$ in the highest, moderate, and low levels to be analyzed using descriptive-empirical method which is based on the speakers' experiences. This was done to analyze and formulate the semantic types of the subjects of the verb 'lie' and the semantic types of the objects of the phrasal verb 'lie to' and 'lie about' during the period of 1990 until 2012. The theories are based on the corpus linguistics theory suggested by Firth (1957), Jones and Sinclair (1974), Sinclair et al. (2004), Cowie (1981, 1994) and Cowie et al. (1993), Stubbs (2002), Nesselhauf (2004), McEnery and Hardie (2001, 2012). For the semantic types, this research refers to the theory of Sinclair (1991), Stubbs (2001), Dixon (2005), McEnery and Hardie (2012), and Hanks (1987, 2013). Lindquist (2009) inspired by Palmer (1933) proposes the adjacent collocation. The book published by Bureau of International Information Programs. U.S. Department of State (2005) was used in order to analyze the correlation between the phenomena of telling lies in America. The results of analysis show that the semantic types of the subjects are the subject as human, human group, human institution, and social group. The semantic types of the objects of phrasal verb of 'lie to' are institution, social group, and social human, human, human group. The semantic types of the objects of phrasal verb 'lie about' are social event, human action, human activity, and various things.
\end{abstract}

Keywords: Adjacent collocation, corpus linguistics, frequency, semantic type

\section{Introduction}

The research of 'lie' had been done by Coleman and Kay (1981). Their research is entitled Prototype Semantics: The English Word Lie. They used the experimental method. They distributed questionnaire pertaining 8 different texts to 71 respondents consist of high school students and college students, the staff officers, and civitas academica of the faculty. The respondents were asked to evaluate those stories into "a lie", "not a lie" and "I can't say"; meanwhile, in order to measure the degree of lying, Coleman and Kay used the scale of 1="very sure not lie" up to 7="very sure lie". Their respondents were English native speakers age between 15-72 years. Gender was not included into the consideration. Those 8 different texts were divided into 2 basic stories; one story consisted of someone was telling lies and the other one was telling the truth.

This research is different from that of Coleman and Kay's (1981). Coleman and Kay's research is motivating this research to investigate the verb 'lie'. The phenomena of telling 
lies is observable through languages such as through the verb 'lie' syntagmatically (in Citraresmana, 2014). This research analyzes the verb 'lie' using corpus linguistics. The researcher tries to analyze the semantic types of subjects and objects of the phrasal verb 'lie to' and 'lie about'; therefore there will be the result of who lie to whom and about what.

English learners usually look up the dictionary in order to find out the meaning of the words. However, dictionary has its own limitation. It only puts the list of the meaning definition with lack of the implementation in details. Especially, when the English learners try to figure out what words come up with other certain words. We do understand that not all words combination could be placed altogether. We cannot translate word by word for instance when we translate the text from source language into target language. The understanding of how words combined with other words is very important, not only for the language learners but also for the translators. Therefore, Corpus Linguistics offer a new way out to handle such problem through its method. Corpus Linguistics uses mix-methods i.e. descriptive statistic through the frequency of the occurrences of one word (node word) with the other word (collocate) (in line with Palmer, 1933; Lindquist, 2009). Firth (1957) also proposed of collocation for corpus linguistics; however, he used different method with those of Palmer (1933) and Lindquist (2009).

The source of data is from COCA (Corpus of Contemporary American English). The data were compiled from period 1990-2012. The texts of this corpus were derived from five sources such as popular magazine, newspapers, fiction, academic journals, and spoken through live talk show which was broadcasted by electronic media. Those media discuss social problems occurring in American people; also those media focus on the political and government matters, American national policies, American laws, and economy. Therefore, this research does not focus on who tells lies in individual lives.

Lexeme 'lie' has two categories, 'lie' as the verb and 'lie' as the noun. The verb 'lie' is the most frequent shown up in COCA. According to that finding, this research focuses on the verb 'lie' instead of lexeme 'lie' as a noun. Based on Oxford Advance Learner's Dictionary 8th edition (OALD, 2010), the verb 'lie' which means not telling the truth is the intransitive verb usually followed by preposition 'to' or 'about'. In the dictionary and in the various researches of verbs through corpus linguistics, the formulation of lexical element only reveals pattern and general semantic types. For instance, the verb 'lie' (OALD8, 2010) only explains that the verb 'lie' is followed by the phrase of 'lie to' and then followed by 'somebody', furthermore, the phrase 'lie about' is followed by 'something'. The semantic types of 'something' and 'somebody' through corpus linguistics approach are able to formulate further description into details about the collocation of the verb 'lie'. Through corpus linguistics also, this research will reveal, to the English learners, how to understand the construction of the verb together with other word (in term of collocation).

In this research, the analysis of collocation was conducted using the principle of adjacent collocation. Lindquist (2009:78) says that "Adjacent collocations are different from the collocations we have just looked at in that the collocate occurs immediately to the right or to the left of the keyword. This kind of collocation is therefore closer to real linguistic structures and not a statistical phenomenon to such a high extent as the "window collocations"'. Collocation as the approach of the analysis is defined using frequency, as this method gets along with the understanding of descriptive statistic method.

The approach of collocation in Corpus Linguistics is used to observe the contextual meaning. On the understanding that the meaning does not come up separately, on the other hand, the meaning shown up based on the associative relation in a text. They are used as the basic principle to understand the collocation meaning. 
This research does not try to modify or refuse the previous research. As a matter of fact, this research studies the semantic types used as the subject of verb 'lie'; the semantic types used as the object of phrasal verb 'lie to'; the semantic types used as the object of phrasal verb 'lie about'; and the relation of those semantic types with the situation of American people at that time.

\section{Theory}

\section{Corpus Linguistics}

Corpus linguistics is one of the approaches to analyze the corpora (Kennedy, 1998:1). Corpus linguistics analyzes language based on its daily usage. This approach also analyzes methodology rather than analyzes language aspect which needs certain explanation or description (McEnery and Wilson, 1996:1). According to Lindquist (2009) corpus linguistics is not one of the linguistics' branches since this approach does not discuss language aspect based on any of linguistic field (syntax, semantics, and pragmatics). He argues that corpus linguistics is the method used to analyze language. Different from Lindquist, McEnery and Hardie (2001) is more comprehensive in their views. They explain that corpus linguistics is not linguistics' branch since this approach does not define syntax, semantics, sociolinguistics in advance, this approach attempts to study the usage of language aspects using corpus as the methods.

To conclude, corpus linguistics is a research method which is used to analyze language in every language levels and in linguistics discipline but it does not focus on a certain linguistics branch. This approach also analyzes language from social perspective and does not analyze psychological language (Teubert, 2005: 2-3).

\section{Semantic Types}

According to Hanks (2013: 174) the pattern of language used might experiences alternations through three ways, lexical alternations, semantic-type alternations and syntactic alternation. Hanks also give the example of lexical alternation as the following:

(1) Clutching at straws

(2) Grasping at straws

The words 'clutching' and 'grasping' both are synonymous. As the verb, the meaning of lexeme 'clutch' is (a) to grasp or hold with or as if with the hand or claws use, strongly, tightly, or suddenly'; (b) to seek to grasp and hold <ed at her hand $>$. The phrasal "clutching at straws" in Merriam Webster Dictionary (2003) means something too insubstantial to provide support or help in desperate situation. There is no phrasal 'grasping at straws'. In here, we can assume that this is a kind of lexical alternations.

Furthermore, Hanks (2013:173) gives the example of semantic alternation below:

(3) Treating injured people

(4) Treating their injuries

(5) Treating their injured limbs

The example of (3) means someone treat the people who got injured in general; the example of number (4) means someone treat the part of body who got injured; while in number (5) someone treat part of the body who got injured especially in the limbs (partonomy).

The form of syntactic alternations as Hanks (2013:173) proposed is as followed:

(6) He broke the window 


\section{(7) The window broke}

Both of the examples above show the occurrence of 'states of affair'. In number (6) the subject 'he' is the actor who broke the window. Meanwhile, in number (7) shows the result of the action. It does not describe the process of the action and also the actor is so biased, we have no idea who did the action.

Based on the example proposed by Hanks (2013) above, it shows that the usage of active or passive depends on the speaker's intention. It depends on what is the aim of the speaker using certain type of structure. However, according to Hanks (2013) there is any possibility of alternations in which one word is combined with other 'rare/odd' word. In this case, this combination of words is a kind of 'exploited form'.

\section{Lexical Alternation}

Lexical alternation is seemingly the form of emphasizing. These forms of emphasizing, which are varied, will influence the meaning. Hanks and Jezek (2010) in (Hanks, 2013:176) analyzed the verb 'attend'. The verb 'attend' has a set of slot to direct object and the verb 'attend' causes the occurrence of semantic type [[Event]]. This finding is understandable through the usage of the verb 'attend' in social community.

(8) People attend a <meeting, conference, funeral, weeding, ceremony, lecture, seminar, class, course, hearing, church service, reception, briefing, inquest>

In other example, Hanks and Jezek (2010) also shows us their findings that there are sets of slot which cannot be fulfilled by [[Event]] but it can be fulfilled by [[Location]]. However, if we observe in closer this semantic type [[Location]] refers to [[Event]]. Take a look at the example as followed:

(9) One attends a school [[Location] $]$ in order to attend the [[Event]]s that take place there.

\section{Semantic Type Alternations}

This semantic type alternations shows in different contexts in a lexical series with different semantic type. This alternation occurs in an action in such cognitive way, for example in the verbs 'think', 'say', 'propose', 'negotiate', 'decide', 'implement' etc. (Hanks, 2013:177). This alternation also shows in subject with the slot between [[Human]] and [[Human Institution]], as below:

(10) Roosevelt ([[Human]]) implemented a New Deal.

(11) The administration ([[Human Institution]]) implemented a New Deal.

According to Hanks (2013:177) the alternation form [[Human Institution]] shows regularly with [[Social Location]], see the examples below

(12) Washington [[Social Location]] implemented a New Deal.

(13) The USA [[Social Location]] implemented a New Deal.

Hanks (2013:178) use the symbol ([[...]]) to describe the relation between semantic type and context. Semantic type alternation for instance [[Institution]] or [[Human Group]] is a form of alternation [[Human]]. This type mostly appears in subject with the verb of cognitive (cognitive action). According to Hanks (2013:178) almost all action which is done by human is a cognitive action. He further argues that we can see the cognitive action through the verbs 'hope', 'discuss', 'negotiate', 'buy', 'sell', 'ask', 'say', 'declare', etc.

The alternation of semantic type also occurs in physical action. In this case, the semantic group [[Human]] could be replaced by [[Animal]]. However, this alternation is still 
in limited scope. This happens due to lexical element as semantic type especially a noun is not a good predictor. A good predictor in semantic type is the verbs. The understanding of semantic type is used in this research to figure out the participants who frequently told lies.

According to Dixon (2005:82) semantic type is formed from the associative relation between the verb and the noun, the relation between the noun and the adjective, and also the relation between adjective and adverb. Therefore, Dixon (2005:82) divides semantic types related to the noun into 4 categories as below:

(1) CONCRETE reference, e.g. 'girl', 'horse', 'wrist', 'piece', 'grass', 'star', 'fire', 'hill', 'city', and 'table'. This type still can be divided into HUMAN; ANIMATE; PARTS, INANIMATE. INANIMATE is divided into FLORA; CELESTIAL and WEATHER (eg. Sun, wind, shade); ENVIRONMENT (eg. Air, water, stone, oil, gold, forest); ARTEFACTS (eg. Building, market, door). HUMAN is descendent into SOCIAL GROUP (eg. Nation, army, crowd, company) and KIN (eg. Father, daughter, uncle, wife).

(2) STATES (and PROPERTIES). This state and properties includes mental attitude and physical attitude. In mental attitude, it can be shown from the word 'pleasure', 'joy', meanwhile in physical attitude, it can be shown from the corporeal or physical form for example 'ache', 'strength'. This group is derived from basic noun such as 'anger' and 'hunger', however this group is majority derived from adjective, for example 'jealousy' and also derived from verb, for example 'delight'.

(3) ACTIVITIES. This group is formed from basic noun for example 'war', 'game' but majority they are derived from the verbs, such as 'decision', 'speculation', 'whipping', 'sale'.

(4) SPEECH ACTS. It shows such in the form of question, order, report, description, talk, promise. In this group noun has something to do with the verb and usually cognitive verb such as 'answer', 'congratulat(ion)', with the exceptional of 'question/ask'.

The understanding of the semantic type proposed by Dixon (2005) above is considered to be the tools of analysis in this research.

\section{The American Condition in 1990 until 2012}

For the majority of American people, in the year of 1990, it was the year of peace, prosperity, and wealthy. In this era there were lots of changes especially in technology. Furthermore, at that time, it was considered as the symbol of the end of cold war and the sign for the beginning of the revolution namely 'Reagan Revolution' and it was also the signal for the Democrat to grab his own seat in the Presidential (in book of Outline of U.S. History, 2005:322).

In the year of 1990s, the majority of American people were long for the traditional value. They were eager so much to have family which was based on the trusted and faith. According to David Brook, the author of New York Times, United States at that time was trying to build a moral construction. The morality of American people at that time was decreasing sharply in the end of 1960s and 1970s and the lack of morality was still being continued and getting worst in the year of 1980s. The cold war era was ended and the number of criminalist was decreasing, however the decreasing of criminalist did not affect the American political situation at that time. As soon as the cold war was ended, then there came the other problem; that was terrorism.

In the era of 1980s the white collar crime and blue collar crime were still existed. It still happened until the year of 1992, even though the economic condition was getting better. In the year of 1992, George Bush went into the Presidential election for the second times. At that time Bush's rival was a young man in 46 year of age, Bill Clinton. Bill Clinton at that 
time had a position as the Arkansas Governor for 12 years. Clinton's background was a civilian; meanwhile Bush's background was a military. Clinton focused on the economic nation's progress, education, and health program rather than the international political affairs. However, as the President, Clinton had bounded with the government rules and regulations. United States is not the independent country. United States is the interdependent and interconnected country. As the President, Clinton had a pressure from the Congress, Senate and their allied nations, in addition the important position of United States in United Nations concerning foreign political affairs.

Clinton had to deal with the foreign political affairs, especially the matters of terrorism issue. Clinton had to be prepared with the preventive action from the countries which had a potential in bringing about the terrorists into America. The American political issues or American foreign policies are not going to discuss in this research. The core issue here is the 'not telling the truth' issue happened in the era of the President Bill Clinton at that time. Clinton, in his propaganda, put forward the family values and emphasized the family matters such as trusted and faith. Unfortunately, he had an affair with other woman. This was against his propaganda, considering Clinton as a married man and he was the President of the United States. Nevertheless, Clinton denied that he had an affair with other woman. Clinton's denial was believed by the American people as a lie. This American society condition is basic information for the analysis, especially to figure out the relation between those semantic types with the situation in American society at that time.

\section{Method}

This research uses the collocation as the method of analysis. This method of analysis is used in order to observe the relation between the node words with its collocation. There are two types of collocation; the collocations in windows proposed by Firth (1957) and the adjacent collocation proposed by Palmer (1933). This research uses the adjacent collocation proposed by Palmer (1933) instead of the collocations in windows proposed by Firth (1957). The reason why theory proposed by Palmer (1933) is chosen due to Palmer (1933) used descriptive statistic, in line with the concept of this research, meanwhile Firth (1957) used statistic approach as a quantitative method.

Different from the collocation in windows, the adjacent collocation observes collocates which appear directly on left or on right side of the node words (Lindquist, 2009:78). This adjacent collocation is very much closer with structural linguistic since the occurrence of collocates based on the frequency. The adjacent collocation analyze what subject appear on the left side of the verb 'lie' and what object appear on the right side of the phrasal verb 'lie to' and 'lie about'.

The scope of the study in this research is based on the theory of Corpus Linguistics proposed by Lindquist (2009). Lindquist's understanding of this discipline refers to Palmer (1933) and also this research uses the definition of Corpus Linguistics proposed by McEnery and Wilson (1996) and McEnery and Hardie (2001). This research also uses the understanding of semantic types from Sinclair (1991), Stubb (2002), McEnery and Hardie (2012), and also Hanks (2013).

In order to have a comprehension view of American society, we refer to the book of Outline of U.S. History (2005). This book consists of 15 chapters. The writing of the book is started by telling about the history of the beginning of America until America in 21st century. Since the corpus is collected from 1990 until 2012, hence the discussion is focused on the condition of America during period of 1990-2012. 


\section{Findings and Discussion}

\section{Coleman and Kay's Findings}

Since the research of 'lie' had been done by Coleman and Kay (1981), it is necessary to discuss Coleman and Kay's perspective from their research. Coleman and Kay tried to define what is 'lie'. When we say that 'lie' is not telling the truth, according to Coleman and Kay, that was not always true. Coleman and Kay tried to more careful in saying that 'telling lies' is the same as 'not telling the truth'. They tried to prove it by using prototype semantics. They did not use 'necessity' and 'sufficient' in order to find out the element of 'lie'.

Furthermore, Coleman and Kay (1981:28) in Linguistic Society of America figured out the elements of telling lies, where the speaker (S) asserts some proposition $(\mathrm{P})$ to an addressee (A):

a. $\mathrm{P}$ is false.

b. $\mathrm{S}$ believes $\mathrm{P}$ to be false.

c. In uttering $\mathrm{P}, \mathrm{S}$ intends to deceive $\mathrm{A}$.

Therefore, 'lie' is considered of not telling the truth, if it consists of the elements (a) falsehood; (b) deliberate; and (c) intended to deceive.

As mentioned before, that Coleman and Kay's research was based on the experiment. In the pre-test, they found out that the subjects tended to circle 'very sure' even when they were not sure at all (Coleman and Kay, 1981:30). They configured the answer based on the respond and reaction of the respondents. They took long answers, hesitated, mumbling, or frowning.

The result pertaining in Coleman and Kay's research gives us the idea that it is not easy to define that someone is telling lies, unless the speakers have those three elements, there is falsehood, deliberate, and there is also the intention to deceive. From the three elements, the last element 'intend to deceive' is perhaps the most influencing. This research is different from what Coleman and Kay did. This research does not measure the degree of telling lies. This research also does not discuss about the elements fulfilled the definition of telling lies. However, their result and the comprehending of the prototype semantics of the English word 'Lie' will be adapted to our discussion further.

\section{Semantic Type of Subject}

Semantic type of subject is divided into the subject of Pronoun and Noun. There are about 225 tokens (tokens is a single linguistic unit, most often a word, although depending on encoding system being used, a single word can be split into more than one token for example 'he's $\rightarrow$ 'he' + 's, as cited in Baker and Hardie, 2006:159); that personal pronoun 'he' occurs in the corpus related to the verb 'lie'. This personal pronoun 'he' shows $15,5 \%$ from the total of the occurrences. The rest is personal pronoun 'he' occurs with the verb 'lie' with the meaning of recline or lie down. In this personal pronoun subject 'he' shows semantic type as [[Human]] and [[Human Institution]].

There are about 174 tokens of personal pronoun 'I' occur in the corpus. This personal pronoun subject 'I' mostly appear as [[Human]]. The personal pronoun subject 'you' occur about 969 tokens. This personal pronoun subject 'you' appears as [[Human]], [[Human Institution]]. Pronoun subject 'they' also occurs as much as 334 token. This pronoun subject 'they' appears as [[Human Group]], [[Human Institution]], [[Social Group]].

For the semantic type of noun subject, it shows in the corpus that subject 'man', 'people', 'president', and 'woman' occur frequently. Each of noun subjects occur as much as 174 tokens, 74 tokens, 120 tokens, 115 tokens respectively. The semantic types of each of noun subject are as follows; (1) noun subject 'man' as [[Human]] and [[Human 
Institution]]; (2) noun subject 'people' as [[Human]] and [[Social Group]]; (3) noun subject 'President' as [[Human Institution]]; (4) noun subject 'woman' as [[Human]].

Below are the description of semantic types with the subject pronoun 'he'.

(1) 'voters say if he [[Human]] lied about an extramarital affair [[Social Event]]'

(2) 'State attorneys and FBI agents to get the president because he [[Human Institution]] lied about having sex [[Social Event]]'

(3) 'credibility has so suffered by his Aug.17 confession that he [[Human Institution]] lied about the Lewinsky affair [[Social Event]]'

Those semantic types are formulated into semantic types as follows:

Table 1 Semantic Types of Subject Pronoun "He + lie about"

\begin{tabular}{|l|l|}
\hline Pattern & Semantic Types \\
\hline Pattern 1 & $[[$ Human $]]$ lied about [[Social Event $]]$ \\
\hline Pattern 2 & $[[$ Human Institution $]]$ lied about [[Social Event $]]$ \\
\hline
\end{tabular}

Mostly, the target of telling lies conducted by subject pronoun 'he' is Human Institution. Those Human Institutions refer to the department concerning of Law, Justice, Police, and Politician, as described below:

(4) 'he [[Human]] lied to US district Judge Henry Hudson [[Human Institution]]'

(5) 'he [[Human]] lied to the FBI and lied to Department of Justice investigators [[Human Institution]]'

(6) 'he [[Human]] lied to the other judges [[Human Institution]] in the case'

(7) 'he [[Human]] felt pressured to lie to the police [[Human Institution]] in order to help his family'

(8) 'he [[Human]] lied to Congress [[Human Institution]] about the Iran-contra affair'

Based on the data above, it can be formulated into the following semantic types:

Table 2 Semantic Types of Pronoun Subject "he + lie to"

\begin{tabular}{|l|l|}
\hline Pattern & Semantic Types \\
\hline Pattern 3 & {$[[$ Human]] lied to [[Human Institution]] } \\
\hline
\end{tabular}

Semantic Type of Object of Phrasal Verb 'lie to'

Based on analysis, it is shown that the object consists of pronoun and noun. This pronoun and noun object is the goals or the target of subject who told lies to. The objects of phrasal verb 'lie to' are (a) [[Institution]], (b) [[Social Group]], (c) [[Social Human]], (d) [[Human]], and (e) [[Human Group]].

The object [[Institution]] as the target consist of (a) 'the police' (16 tokens); (b) 'grand jury' (10 tokens); (c) 'judge' (7 tokens); (d) FBI (6 tokens); (e) 'investigators' (5 tokens); (f) 'Congress' (4 tokens); (g) 'President' (2 tokens); (h) 'Government Officials' (1 token); (i) 'courts' (1 token); (j) ‘commanders' (1 token); (k) 'Senate Committee' (1 token); (l) 'Law enforcement authorities' ( 1 token); (m) 'Secretary of Defense' (1 token). Based on those findings, it can be concluded that subjects tend to tell lies to the [[Institution (Executive) (Legislative) (Judicature)]]

The objects [[Social Group]] as the target consist of (a) 'American people' (12 tokens); (b) 'friend' (6 tokens); (c) 'nation' (5 tokens); (d) 'people' (4 tokens); (e) 'publics' (4 tokens); (f) 'profession' (4 tokens); (g) 'pollsters' (2 tokens); (h) 'neighbor' (1 token); (i) 'fans' ( 1 token). Based on the findings above, it can be concluded that subjects whether as [[Human]] or [[Human Institution]] tend to tell lies to [[Social Group]]. 
The objects [[Social Human]] as the target consist of (a) 'mother (10 token); (b) 'wife' (6 tokens); (c) 'husband' (5 tokens); (d) 'father' (4 tokens); (e) 'parents' (4 tokens); (f) 'family' (3 tokens); (g) 'kids, son, baby girl' (3 tokens). The object [[Human]] as the target consist of (a) 'me' (162 tokens); (b) 'him' (39 tokens); (c) 'her' (19 tokens); (d) 'proper name' (12 tokens); (e) 'myself' (3 tokens). The objects [[Human Group]] as the target consist of (a) 'us' (47 tokens); (b) 'them' (11 tokens); (c) 'everyone' (2 tokens). Based on the findings above, it can be concluded that subjects [[Human/Human Institution/Human Group]] tend to tell lies to other human as in their social lives [[Social Human]].

Based on the findings and data above, it can be formulated into table 3 below:

Table 3 Semantic Types of Object of Phrasal Verb "lie to"

\begin{tabular}{|l|l|}
\hline Pattern & Semantic Types \\
\hline Pattern 4 & Subject lied to [[Institution]] \\
\hline Pattern 5 & Subject lied to [[Social Group]] \\
\hline Pattern 6 & Subject lied to [[Social Human]] \\
\hline
\end{tabular}

\section{Semantic Type of Object of Phrasal Verb 'lie about'}

The topic of phrasal verb 'lie about', based on the analysis, is shown as [[Social Event]], [[Human Action]], [[Human Activity]] and [[Various Things]]. This 'social event' consists of 'sex and affairs' (12 tokens). The [[Human Action]] consist of (a) 'age' (36 tokens); (b) 'personal matters' (11 tokens); (c) 'something' (6 tokens); (d) 'their own action' (5 tokens); (d) 'money' (4 tokens). The [[Human Activity]] consist of (a) 'everything' (10 tokens); (b) 'one thing' ( 2 tokens). The [[Various Things]] consist of 'various matters'. This 'various matters' is shown from pronoun 'it' (21 tokens), pronoun 'that' ( 7 tokens), and pronoun 'this' (2 tokens).

Based on the findings above, we can see that the topic mostly American people lied about were [[Social Event]]. The American people, based on the text appeared in the corpus, never tell the truth about their having sex and affairs. It is human also that people never tell the truth about their activities [[Human Activities]]. Furthermore, people tend to tell lies about everything not in a particular [[Various Things]].

\section{The Phenomena of Telling Lies of the American Society in the Era 1990-2012}

On the understanding of the data and findings above, we can see that the phenomena of telling lies typically humanize. It happens not only in America but also in any other globe. However, this research discusses the phenomena of telling lies in America.

People, as subjects [[Human/Human Group/Human Institution/Social Group]], told lies. They told lies about their having sex or affairs, their activities, and also they told lies about everything not in particular. So, it is obvious that people in America do not tell the truth about their personal lives. People also in America told lies to the Institution, social group, and social human. The target of 'telling lies to' were the police and the people who worked in the government, as the executive board of nation and as the executive of justice, the other target of being told lies also the people who got involved in the politics.

Based on the analysis, we can draw a picture that people in America in their social lives rarely tell the truth about their personal lives. The people who got caught in a crime action tended to tell lie to the police and/or FBI and they denied their action to the judge and the grand jury. In the social situation, American people, people, nation, and publics are the target of being told lies; on the other hand in the political situation, the Congress, President, Government Officials, and Senate Committee are the target of being told lies. As social human, people in America tended to tell lies to the person with a close relationship such as mother, wife, husband, parents, family, kids and so forth. 


\section{Conclusion}

Based in the findings and discussion, it can be concluded that semantic types of subject who told lies in corpus are (i) [[Human]]; (ii) [[Human Group]]; (iii) [[Human Institution]]; (iv) [[Social Group]]. The semantic types of object of the phrasal verb 'lie to' are (i) [[Institution]]; (ii) [[Social Group]]; (iii) [[Social Human]]; (iv) [[Human]]; (v) [[Human Group]]. The semantic types of object of the phrasal verb 'lie about' are (i) [[Social Event]]; (ii) [[Human Action]]; (iii) [[Human Activity]]; (iv) [[Various Things]].

The findings of Coleman and Kay's research revealed three indicators that the people tell lies,
a. $\mathrm{P}$ is false.
b. $\mathrm{S}$ believes $\mathrm{P}$ to be false.
c. In uttering $\mathrm{P}, \mathrm{S}$ intends to deceive $\mathrm{A}$

This recent research might give a completion to Coleman and Kay's. The people in America accused someone else of being told lies since they believed that the proposition contain three indicators $\mathrm{P}$ is false; $\mathrm{S}$ believes $\mathrm{P}$ to be false; and In uttering $\mathrm{P}, \mathrm{S}$ intends to deceive A.

\section{References}

Aijmer, K. and B. Altenberg (eds.). 1991. English Corpus Linguistics: Studies in Honour of Jan Svartvik. London: Longman.

Baker, H. and McEnery. 2006. A Glossary of Corpus Linguistics. Edinburgh: Edinburgh University Press.

Coleman and Kay. 1981. Prototype Semantics: The English Word Lie.

Dixon, R. (n.d.). A Semantic Approach to English Grammar. New York: Oxford University Press.

Firth, J. 1957. Studies in Linguistics Analysis 1930-1955. Philological Society; Special Volume, 1-32.

Halliday, M. 1978. Language as Social Semiotic. London: Edward Arnold.

Halliday, M. 1991. Corpus Studies and Probabilistic Grammar. In K. Aijmer, \& B. Altenberg (eds.), English Corpus Linguistics, 30-43.

Hanks, P. 1987. Definitions and Explanations. In J. Sinclair (ed.), Looking Up (116-136). London: Collins.

Hanks, P. 2013. Lexical Analysis.Norms and Exploitations. Cambridge: MIT Press.

Kennedy, G. 1998. An Introduction to Corpus Linguistics. London: Longman.

Lauder. 2009. A Collocation Analysis of Keywords in a News Media Corpus: The Role of Lexis in the News Agenda and Issue Representation.

Lindquist, H. 2009. Corpus Linguistics and the Description of English. Edinburgh: Edinburgh University Press.

McEnery and H. Baker. 1996. Corpus Linguistics: An Introduction. Edinburgh: Edinburgh University Press.

McEnery and H. Baker. 2012. Corpus Linguistics. Cambridge: Cambridge University Press. 
McEnery, and Wilson. 2001. Corpus Linguistics: An Introduction. Second Edition. Edinburgh: Edinburgh University Press.

Palmer, H. E. 1966. Second Interim Report on English Collocations. Tokyo: Kaitakusha. 